\title{
Exposition of Process-Based Learning for First Year University Students
}

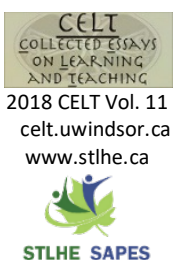

STLHE SAPES

\author{
Bettina Callary, Patrick Maher, Emily Root, Jennifer Ryan \\ Cape Breton University
}

DOI: $10.22329 /$ celt.v11i0.4941

In this expository essay, four faculty members co-reflect on the pedagogy used within one firstyear course at a small Canadian university. We discuss the responsibility of facilitating five process-based pedagogical approaches. These complex and interrelated processes include: i) self -directed learning, ii) reflexive intra-personal learning, iii) group/inter-personal development, iv) experiential learning, and v) community-based and/or service learning. We describe and give examples of how these approaches help students learn how to learn, function, and grow respectfully with one another and with community.

Dans cet exposé explicatif, trois professeurs réfléchissent ensemble à la pédagogie en usage dans l'un des cours de première année d'une petite université canadienne. Ils abordent la question de la responsabilité en matière de facilitation des approches pédagogiques fondées sur un ensemble de cinq processus. Ces processus, complexes et interreliés, sont les suivants : i) l'autoapprentissage, ii) l'apprentissage réflexif intrapersonnel, iii) le développement interpersonnel ou de groupe, iv) l'apprentissage par expérience et v) l'apprentissage fondé sur les services ou sur la communauté. Au moyen d'exemples, nous montrons comment ces approches aident les étudiants à apprendre à apprendre, à agir et à grandir dans le respect des uns et des autres ainsi que de la communauté.

$\mathrm{T}$ he Bachelor of Arts Community Studies (BACS) degree is offered at Cape Breton University (CBU) on Cape Breton Island in Nova Scotia. Within the degree, students take a core suite of courses in Community Studies (COMS). The pedagogy used in the COMS courses effectively enables students to use adult learning principles (Knowles, Holton III \& Swanson, 2012) because of the small group environment promoting interaction, problem solving, collaboration, and group commitment (see Connell \& Seville, 2007; Maher \& Root, 2015).
COMS 1100 is capped at 18 students. The learner-centred style places experience as fundamental to learning, and always includes personal reflection on that experience. Students work collaboratively to focus the content of their learning, and move that learning into the community. Community-based research practices are a growing trend in academia, especially in higher-level courses such as at the third and fourth year of undergraduate programs (Etmanski, Hall, \& Dawson, 2014); the BACS degree, and in particular the required COMS courses at its core, is unique in that this practice begins in the 
first year and extends as a progression across the degree.

The BACS degree began in 1975: "To give students the opportunity to develop skills and to be made aware of how problems are analysed and solved in the real world" (Morgan, 2004, p. 72). Indeed, CBU's mandate has always been grounded in its community, with "more community-based programs [than other institutions], especially those interfacing with local industry for community development" (p. 76). The BACS degree has maintained its tight-knit relationship with the local community and that enables students to work in the community both on core course projects as a group, and in work placements individually. Social work projects have always been popular, exploring topics such as substance abuse, violence against women, and poverty. Students have sought out these topics, which they felt were important, undesirable issues within their communities. Cape Breton Island is rich in culture and beauty, but there was and continues to be a very real struggle exhibited in community life. Cape Breton's economy experienced depression and recession after coal and steel industries disappeared. While many left in search of work, families also stayed in Cape Breton, but experienced decades of political posturing and 'band-aid' investments that did little to support the growth and wellbeing of the economy and that contributed to feelings of marginalization and stigmatization of the Island.

In the past five years, we have seen a turnover of five out of seven full-time faculty in Community Studies. The new faculty members (including these authors) have a collaborative and appreciative inquiry method to community-based research. While many of the pillars in COMS 1100 have remained the same (e.g., group dynamics, self-direction, community engagement), the ways in which the students explore these topics may have changed, which has spurred reflection on scholarship of the pedagogy used in COMS 1100. We explore how community-based research provides a service to the community, while also teaching students to work with one another and with community members to understand the complexity of social change through service using selflearning and self-reflexivity. We are conscious of taking this approach, as also outlined in work with disadvantaged groups such as Indigenous cultures in Northern Canada (Rasmussen, 2015), and neighbourhoods in inner city Toronto (Ryan, 2016).

In the following sections, we describe and give examples of how: a) group dynamics, b) selfdirected learning and intra-personal learning, and c) experiential approaches in community-based learning all converge in COMS 1100, help students learn how to learn, function, and grow respectfully with one another and with community.

\section{Group Dynamics in COMS 1100}

Group dynamics, as a pillar in all COMS courses, is the "glue" that holds things together. The activities and discussions in which students engage in COMS 1100 are the start to that process. The faculty are facilitators who assist in creating a meaningful learning environment. Many core tenets of this relationship build upon the outdoor educator/coaching background of the current faculty members.

From outdoor and experiential education, comes much literature on the notion of conscious community building. Frank (2004) produced an excellent "road map" to community building, complete with educational foundations for collaboration and co-creation. Frank connects the conversation to the thinking of earlier scholars such as Kurt Hahn and John Dewey, but also encourages educators to simply go where their own communities dictate. This is where COMS 1100 begins. Students are encouraged to start their foray into 'what is community?' by developing a community within the classroom. Every one of our "caring classrooms" is unique and needs different insights and constructs in 
its journey that requires ongoing support and nurturing.

Employing the seminal works on theoretical group constraints of Lewin (1948) and the sequential stages of group development established by Tuckman (1965) and O'Connell and Cuthbertson (2009) moved the discussion to one of "conscious groups" as a means whereby personal growth of a group member is in line with other aspects of group productivity. In COMS 1100 we assist everyone to seek to grow from their experiences, striving to learn about themselves and the whole community. O'Connell and Cuthbertson offer an excellent overview of experiential education literature and provide a variety of activities for use.

\section{Key Group Process Activities}

To intentionally start the group process, which is also already informally happening, we use a number of activities. There is a wealth of activity literature available (see Project Adventure http://www.pa.org and their three comprehensive "classic" texts: Quicksilver, Silver Bullets, and Cowstails and Cobras) and we further encourage all facilitators to also create their own activities. Two activities we have used since September 2014 are: the Silent Opera and the Group Pencil Maze. These two activities stress different concerns we see when building community (groups) in our classrooms - they can ladder together as part of a group progression, but can also stand alone as needed.

\section{Activity One: Silent Opera.}

The activity requires a group to communicate a set of instructions for completing three simple tasks to a person who is blind-folded. For example, the tasks could include locating and picking up a ball or jumping into a hula-hoop. The catch is that the message must be communicated without speaking (by using actions) to an intermediary who may speak, but who does not know what the tasks are, nor is able to see the blindfolded person. Inevitably the entire group experiences communication frustrations including the inability to communicate a consistent message, challenges interpreting/receiving a message, and the confusion of non-verbal communication. A debrief of the activity allows participants to review what occurred and share the frustrations and successes that they experienced. Once they have debriefed, participants are encouraged to think about how what they learned about communication may be relevant to their group's ability to function and communicate through other real-world tasks.

\section{Activity Two: Group Pencil Maze.}

In this activity, participants stand shoulder to shoulder in a circle. Participants are each given one standard, unsharpened pencil. To begin, they arrange themselves so that they suspend one pencil between each two people in the circle. The pencils must be held by the touch of the fingertip only. The group is then instructed to walk a certain distance (and often around an obstacle) and back to their starting position without dropping any pencils. Should a pencil drop, the group is required to begin again. The task becomes challenging as the circle morphs and spreads out while the participants walk. To be successful, the group needs to negotiate dynamics such as communication, leadership, cohesion, cooperation, problem-solving and persistence. The activity can be debriefed to discuss those aspects of group process or whatever specific dynamics may arise. One nice aspect of this activity is that is takes very little preparation and only a box of pencils for equipment.

Further thoughts on the use of these activities and the progression can be found in Maher and Root (2015). These activities establish rapport and help to create community, but they must be supported by a degree of continued nurturing. A community in the classroom needs ongoing care to flourish at the end of 
first semester, the end of first year, and throughout a student's university degree. One would hope that such community also encourages life-long learning and a sense of conscious citizenship.

\section{Group Dynamics in COMS 1100}

As the second pillar of the COMS pedagogical experience, self-directed learning can be defined as learners both self-teaching and assuming ownership of their learning, so that there is an "internal change of consciousness in which the learner sees knowledge as contextual and freely questions what is learned" (Knowles et al., 2012, p. 184). Knowles and colleagues further state that adults place great importance on the sense of personal autonomy, or their ability to choose their learning strategy. In COMS courses we intentionally build the student's capacity for, and skills in, self-directed learning. We also assist students to become more aware of their own motivations in learning and of the pitfalls and possibilities of self-directed approaches to learning.

This section describes three assignments that help to shift students towards becoming increasingly self-directed. The gradual and intentional progression is important because students often enter university having experienced very conventional teacherdirected learning throughout their former schooling. As COMS faculty members, our role in first year is to help students become familiar with, and adept at learning through, our pedagogy so that they can be successful in subsequent years in the BACS degree.

\section{Key SDL Activities and Assignments}

There are three key assignments in COMS 1100 that support students to become effective self-directed learners. The first two activity-assignments take place in first term and prepare students for a self-directed project of larger scope in second term.
Assignment One: Exploring Learner Identities.

This activity-assignment begins with a day of reflective art-making and small group dialogue that assists students to reflect on who they are as learners and how prior life experiences to this point have shaped their preferred learning styles, their attitudes about learning in and out of school, and their capacity for self-motivation towards life-long and life-wide learning. This type of self-awareness about one's learning identity can help strengthen a student's capacity for self-directed learning (Jarvis, 2009; Knowles et al., 2012).

In the preparatory activity, the classroom is divided into six small group stations. At each station is a different question and a different art medium. Students dialogue in small groups while they each create an artistic response to the prompting question at their station. At regular intervals of approximately ten or fifteen minutes, group members are shuffled to new stations with new students and begin again with a new reflection question and a new art medium. See Appendix A for the reflection questions as they are presented to the students.

As they engage in the creative reflection activities students are reminded that their artistic explorations are not being assessed. After the students have participated in the full round of stations, the assignment is to write an autobiographical essay elaborating on how their life experiences have shaped their identities as learners. This helps them recognize that they have always been agents of their own learning throughout their lives, often in informal settings. This recognition can build confidence for students who have not experienced deep success in formalized schooling contexts, while students with strong formal academic backgrounds can begin to recognize the value of life-wide informal learning experiences. 
Assignment Two: Community Adventure in Curiosity.

With a new-found or deepened appreciation for learning that takes place in informal contexts, and a stronger sense of themselves as 'learners-in-theworld,' students are tasked with the next assignment. In this assignment, students work in groups of four, to explore a local community during one afternoon outing. The 'community' is generally a geographic neighbourhood in the municipality; however, the assignment would work in other community contexts.

Students are asked to delineate the boundaries of their chosen neighbourhood on a map. Next they engage in place-based learning to accomplish several challenges, scavenger-hunt style. This often takes students out of their comfort zones by requiring them to talk with community members spontaneously or interact with people outside of their usual family or peer group. The challenges are meant to help them recognize that learning opportunities are all around them and that learning can take place anywhere at any moment if they become attuned to their own curiosity and interests. The questions and challenges are presented in Appendix B.

The questions and challenges provide some general direction, but they are intentionally very open-ended and therefore full of choices for the students to make; students can go wherever they want and speak with whomever they want. Without a doubt, students consistently report two key learnings from their adventures in curiosity. First, they are surprised at how helpful and enthusiastic general members of the public are to share their stories and teach or learn with the students. Secondly, they are often astounded at the depth and breadth of understanding that is possible to acquire through open-ended, contextual, place-based learning. They frequently state that learning is so much more enjoyable and meaningful when they go to the place, person or organization. Through this activity they often experience newfound appreciations for their own communities that they had previously assumed to be boring or mundane.

While it may seem as though this activity is more closely related to some of the other pillars of the COMS courses, such as experiential or communitybased learning, it does play a key role in developing students as self-directed learners. The list of scavenger-hunt-style tasks, or questions on the assignment page, quickly become rather irrelevant as the students become genuinely engaged in learning about the people and places of their chosen neighbourhood. The scavenger-hunt questions, rather than directing students' learning, becomes the tangible aid that gives students an excuse to talk to people and the confidence to explore. When they receive curious responses from members of the public, they can state that they are 'doing an assignment.' In this way they can be self-directed in their learning without having to take on the responsibility of fully understanding or explaining self-directed learning to others; we invite them to experience it first to build their confidence.

\section{Assignment Three: Group Directed Community- based Learning Project.}

The final assignment presented is the simplest in terms of the direction provided, and the most complex in terms of students' experience of selfdirection. The assignment is for students to learn about, through experiential, community-based and scholarly inquiry, any community-related topic of their choosing, and to teach their peers about their findings. The deliverable is for them to teach two full classes (3 hours) on their community-related topic, incorporating activities, readings, guest speakers, multi-media or other components.

The first step as a facilitator is to facilitate a brainstorming process and help the group reach consensus about their chosen topic, broadly. We often encourage the students to avoid identifying specific rigid learning objectives at the outset and, 
rather, to engage in exploratory community-based inquiry first so as to broaden their awareness of what might be possible to learn. Often the students skip the 'learning phase' and try to sort out the plans for teaching the class. For this reason, we often encourage the students towards planning their inquiry (what activities, interviews, field-trips, will guide their learning) as stage one, and to be patient through the learning phase. We find it can be uncomfortable for students to sit with uncertainty and simply engage in learning for learning's sake. As students begin to experience success and enthusiasm by engaging with community members, they find that the second phase (planning to teach the class) gradually returns to view.

Inevitably, we witness a predictable process: Students often experience an initial enthusiasm for autonomy; subsequent feelings of being overwhelmed by vast possibilities; a gradual realization of the hard work required (which often manifests first in resistance to, and then acceptance of commitment to the project); some fumbling through the planning and implementation of their learning activities and final presentations; and finally a sense of accomplishment and a new-found confidence in their capacity to take responsibility for their learning. Our role as facilitators through this is to recognize when to offer support and when to allow space for students to make educative mistakes. This typically involves listening, observing, posing timely critical questions, offering encouragement, and assisting students to resolve interpersonal conflicts.

\section{Experiential and Community- engaged Learning in COMS 1100}

Many students coming into COMS 1100 carry understandings of their communities (and by extension, themselves) that are very much embedded in, and/or negotiating with, the negative framing of Cape Breton Island that has been described earlier in this paper. Local students may or may not be internalizing that stigma (Campbell \& Deacon, 2006), but there is definitely an awareness of how they are perceived within and beyond their home communities. However, this is also becoming a historical tension, as the local declining population of youth is causing CBU to look further afield for students. More and more international and domestic students from other places in Canada are choosing BACS on campus or online.

Given the incredibly challenging nature of disrupting stigmatized frames, two critical pillars of the COMS pedagogy include experiential and community engaged learning. Together, these approaches provide learning experiences that challenge, problematize, and dilute the negative framing of many Cape Breton communities. Kolb's theory of experiential learning is described as "the process whereby knowledge is created through the transformation of experience" (1984, p. 38). Experiential learning is much more than simply providing hands-on experiences in a learning environment. True experiential learning requires meaningful and engaged reflection that allows the learner to understand, make sense of, and integrate individual learning into new ways of being. As facilitators in COMS courses we acknowledge the existing critiques of Kolb's model of experiential learning (Jarvis, 2009; Miettinen, 2000; Schenck \& Cruickshank, 2015; Seaman, 2008), but recognize its enduring value within our particular learning context.

One of the critical ways experiential learning is integrated into the curriculum is through community engaged learning. Students learn about critical pedagogy of place (see Greenwood, 2008) that requires reflection on the linkages between the lived experiences of communities, how pedagogy informs understandings of place, and how we, as individuals and communities, impact the spaces we inhabit. During the fall semester, students' understandings of community are shifting and stretching; the change can feel slow at times as the negative framing of community is still shaping many conversations. 
Interestingly, this negative framing often contradicts their collaborative experiential learning.

\section{Key Community-Engaged Experiential Learning Activities}

\section{Assignment One: Good News Stories.}

After reflecting on the experiences of facilitating COMS 1100 projects with a negative tone, instructors decided to intentionally design an assignment that supported a more appreciative approach (Cooperrider, 1990) and appreciative pedagogy (Yballe \& O'Connor, 2000). Appreciative learning (Preziosi \& Gooden, 2002) emphasizes reflecting on and celebrating the assets and richness of communities, creating a space for students to reframe notions of community. The first assignment in January asked student groups to seek out, share and reflect on 'good news' stories from their local communities. Students described feeling challenged at the thought of 'good news' but, after taking photographs of good news, finding clippings in newspapers, and engaging in community events, they eventually felt like it was easy and even exciting to find examples of good things happening in the community that helped them to learn about what the community can offer.

\section{Assignment Two: Volunteer Experience.}

The next assignment asked students to reflect on a volunteer or community engagement experience. In one group, students decided to have a collective volunteer experience. They chose Lifeline Syria Cape Breton, a local organization supporting and welcoming Syrian Refugees in Cape Breton that had been featured in two of the 'Good News' stories shared by students. This volunteer experience was deeply meaningful for many students. Not only did students feel proud of their involvement but they also felt more connected to their wider community. Students were making the connections between their own learning, contributing to their communities, and relationship building. A few weeks later they decided to also volunteer with United Way Cape Breton's Winter Gala, which, incidentally, was another of their 'good news' stories. In their reflections on learning many students described these experiences as very impactful but also shared that without the nudge of their peers they would not have volunteered.

\section{Assignment Three: Community Builder.}

In keeping with the appreciative lens, the next project was designed around an asset-based approach to community building (Lerner \& Benson, 2003). This assignment invited students to design a program, service, opportunity, or event for their community that is based on the existing assets and richness of Cape Breton Island. Although they did not have to actually build their proposed project, students were required to engage in all aspects of the building steps - community research, market research, exploring permits and regulations, contacting venues, speaking with governing bodies and developing communications plans.

The first step in this process was to engage in community asset-mapping. This created a space for students to explore what was happening in their communities without focusing on what was broken. Similar to the 'good news' story there was some concern and hesitation around asset-mapping which seemed to suggest, again, the enduring power of the negative framing of community in Cape Breton. However, once students started the process, the culture of the class became much more joyful. Students laughed and shared memories of spaces and places. They talked about what they loved and how they could build on those experiences. No process is ever perfect and it was easy, at times, for groups to slip into thinking about 'what needs fixing' but it became 
easy for them to also get back into dialogue around assets and richness.

The projects pitched by students included music festivals, celebrations of place and culture, experiential tourism, and social enterprise. What was most exciting is that students were often heard asking, 'why aren't we ACTUALLY doing this?' The energy in the classroom had totally shifted from students who seemed discouraged and frustrated when describing their communities to students who were taking responsibility for contributing to change while recognizing the richness of their communities. Yballe and O'Connor (2000) also found a more appreciative approach to learning meaningful content energized students and made them feel more comfortable to speak up.

\section{Conclusion}

Simons and Cleary (2006) found that students participating in community-based experiential learning are more diverse in their attitudes, they are more civically engaged, and they are also more politically aware. Further, Astin, Vogelgesang, Ikeda, and Yee (2000) found that community engaged learning positively impacted academic achievement, leadership skills, career choices, projections of future engagement in service learning and the value youth placed on activism. Given these positive aspects, our aim in COMS 1100 is to develop group dynamics, self-reflection, and the ability for students to engage in self-directed learning in order to build the stepping stones that students need to organize and coordinate experiential learning in the community. This type of "learning community" is recognized as a high impact practice in university courses, which maximizes lifechanging student learning and increases retention across the undergraduate level (see Kuh, 2008 and NSSE, 2015). It is our perception that building selfdirected, personally and socially aware students, students who are passionate about learning in and through their communities and interested in making a difference, can be accomplished through various thought-provoking, positively-framed assignments and activities, even in a first year undergraduate course.

\section{References}

Campbell, C., \& Deacon, H. (2006). Unravelling the Contexts of Stigma: From Internalisation to Resistance to Change. Journal of Community and Applied social Psychology. $16,411-417$

Cooperrider, D. (1990). Positive image, positive action: The affirmative basis of organizing. In S. Srivastva \& D. L. Cooperrider (Eds.), Appreciative management and leadership: The power of positive thought and action in organizations (pp. 91-125). San Francisco: Jossey-Bass.

Connell, J., \& Seville, P. (2007). Process-based learning: A model of collaboration. In A. Hajek \& E. Noseworthy (Eds.), Proceedings of the Association of Atlantic Universities 11th Teaching Showcase; Oct. 28, 2006, Memorial University of Newfoundland (pp. 89-100). Halifax: Association of Atlantic Universities.

Etmanski, C., Hall, B. L., \& Dawson, T. (Eds.). (2014). Learning and teaching communitybased research. Toronto: University of Toronto Press.

Frank, L.S. (2004). Journey toward the caring classroom. Oklahoma City: Wood 'N' Barnes. 
Jarvis, P. (2009). Learning to be a person in society. London, UK: Routledge.

Knowles, M. S., Holton III, E. F., \& Swanson, R. A. (2012). The adult learner (7th ed.). New York, NY: Routledge.

Kolb, D.A. (1984). Experiential learning. Englewood Cliffs, NJ: Prentice Hall.

Kuh, G. D. (2008). High-impact educational practices: What they are, who has access to them, and why they matter. Washington, DC: Association of American Colleges and Universities.

Lerner, R., \& Benson, P. (2003). Developmental Assets and Asset-Building Communities. New York: Kluwer Academic/Plenum Publishers.

Lewin, K. (1948). Resolving social conflicts: Selected papers on group dynamics. New York: Harper.

Maher, P.T., \& Root, E.L. (2015). Learning to learn: Creating community before cramming in content. In J. Loxton (Ed.). Proceedings of the 2014 Association of Atlantic Universities Teaching Showcase; October 18 2014, Cape Breton University, Sydney, NS (pp. 53-59). Halifax: Association of Atlantic Universities.

Morgan, R. (2004). Perseverance: The story of Cape Breton's university college 1952-2002. Sydney: UCCB Press.

NSSE (National Survey on Student Engagement). (2015). High impact practices. Available at http://nsse.iub.edu/html/high_impact_pract ices.cfm. Accessed on Jan. 2, 2015.
O'Connell, T.S., \& Cuthbertson, B. (2009). Group dynamics in recreation and leisure: Creating conscious groups through an experiential approach. Champaign, IL: Human Kinetics.

Preziosi, R. C. \& Gooden, D. J. (2002). Using appreciative learning in executive education. New Horizons in Adult Education, 16(1), 10-16.

Rasmussen, D. (2015). Cutural Survival, Voices Issue 1.1. Retrieved from https://www.culturalsurvival.org/publicatio ns/voices/derek-rasmussen/cease-do-evilthen-learn-do

Ryan, J. (2016). The violence of low expectations and poor educational outcomes, presentation for the Learning Circle, United Way. Retrieved from

https://issuu.com/actyouth/docs/act_violenc eoflowexpectations

Schenck, J., \& Cruickshank, J. (2015). Evolving Kolb: Experiential education in the age of neuroscience. Journal of Experiential Education, 38(1), 73-95.

Seaman, J. (2008). Experience, reflect, critique: The end of the "learning cycles" era. Journal of Experiential Education, 31, 3-18.

Tuckman, B.W. (1965). Developmental sequences in small groups. Psychological Bulletin, 63, 384-399.

Yballe, L., \& O'Connor, D. (2000). Appreciative Pedagogy: Constructing Positive Models for Learning. Journal of Management Education. 


\section{Biographies}

Dr. Bettina Callary is an Associate Professor in Community Studies, Sport and Physical Activity Leadership at Cape Breton University, and an adjunct professor in the School of Human Kinetics at the University of Ottawa. She holds funding from the Social Sciences and Humanities Research Council of Canada for her research program on coaching adult athletes, and researches topics in coach education, learning, and development and qualitative research methods. She is an Associate Editor for the International Sport Coaching Journal and a guest editor for a special issue for coach developers in ISCJ. She is also an alpine ski coach and coach developer.

Jen Ryan is a community-based researcher located in rural Cape Breton. Her research interests center on how collaborations between educational institutions and communities can support community development processes, contribute to youth wellbeing and re-shape/re-imagine processes of research, teaching and learning. Jen is currently exploring how elementary, junior and senior high school students articulate and understand their relationships to community. She also supports the research and evaluation needs of several community development processes and is an adjunct professor at Cape Breton University.

Patrick T. Maher, Ph.D., is an Associate Professor of Community Studies and Outdoor Leadership at Cape Breton University. Pat is Editor of the Canadian Journal of Environmental Education, Associate Editor of the Canadian Journal for the Scholarship of Teaching and Learning, and former Editor of the Journal of Experiential Education (2010-2016). He is a University Teaching Chair in Community Engaged Teaching and Scholarship (2017-2019), as well as a 3M National Teaching Fellow (2014). As a researcher, two foci of his work include cultural dimensions of outdoor learning, and leadership within teaching and learning in higher education. 


\section{Appendix A}

\section{Who am I as a learner?}

1) Where I learn.

Think about an "ah - hah" moment from your past. A moment when you flourished as a learner, felt a sense of curiosity, or were just generally engaged in what you were doing. Now think about the PLACE where this occurred. Was it at school? Outside? In a neighbourhood? City? Forest? Camp? Using the markers provided draw a map of this learning place. Include a legend to note key spots on your map.

2) Positive and negative learning.

We all experience learning situations that range from negative (or less appealing) to positive and inspiring. Reflect on this continuum in your own life - what factors discouraged or inspired learning. Choose one learning moment from each end of the spectrum and pretend you were able to take a snapshot of that moment. Using the pencils provided, draw one black and white photograph and one full colour photograph to represent these two different experiences.

3) Learning styles.

As a learner you likely have one style (or a couple) that you're most comfortable with. Some of these styles include visual, auditory, experiential, kinesthetic/tactile, readerwriter. Create a poem describing your balance of learning styles.

4) Life-long learners.

Sometimes learning takes a lifetime - using a collage of construction paper showcase something you've learned in stages over a number of years. How did you piece the moments together to make sense of one concept?
5) Teachers and mentors.

We all have teaching or learning mentors people who inspire and support us to learn, to be creative, to follow our passions and pursue our curiosity. Think about someone in your life who has played this role. Paint a watercolour of that person. This may be a realistic painting of them or something more abstract that represents their qualities as a mentor.

6) Cultural learners.

Our own personal and cultural values influence our formal and informal learning. Reflect on your own personal and cultural values and the role they play in your life as a learner. Using the crayons provided draw a mind map that illustrates how these values are interconnected and how they manifest in your learning experiences.

\section{Appendix B}

\section{Community Adventure in Curiosity}

1) Identify as many free resources and/or free opportunities as possible that support citizens' sustainable well-being in this community.

2) Complete a "random act of kindness" that will brighten the day of one stranger who you encounter in the community.

3) Buy a meal for your whole group to share using only the $\$ 3$ that each of you has to contribute. Make your choices based on sufficient quantity, quality, cost, and sustainability (lowest ecological footprint possible). How easy/difficult is it for people in this community to feed themselves sustainably? Why? 
4) Speak with someone who has lived in this community for at least 10 years. Find out how the community has changed in that time. Is it more or less sustainable now? Explain why.

5) Find 2 examples (make a sketch or take a photograph) of the more-than-human world flourishing in this community, and 2 examples where our more-than-human neighbours are struggling to thrive. How might this community better support our non-human neighbours?

6) Identify a business that you feel contributes to the sustainability of the community. Speak to the owner or an employee and find out what factors contribute to the long-term viability of the business. In what ways does the business support local sustainability?

7) Identify 4 elements that are ecologically interconnected. Identify 4 elements that are socially interconnected. Now identify 4 elements that are socio-ecologically interconnected. 